\title{
Lanthanide I on Interaction with a Crown Ether Methacrylic Polymer, Poly(1,4,7,10-tetraoxacyclododecan-2-ylmethyl methacrylate), as Seen by Spectroscopic, Calorimetric, and Theoretical Studies
}

\author{
M. J . Tapia, ${ }^{*,+}$ H. D. Burrows, ${ }^{\ddagger}$ J . M. García, ${ }^{\dagger}$ F . García, ${ }^{\dagger}$ and A. A. C. C. Pais \\ Departamento de Química, Universidad de Burgos, Plaza Misael Bañuel os s/ n, Burgos 09001, Spain, \\ and Departamento de Química, Universi dade de Coimbra, 3004-535 Coimbra, Portugal
}

Received September 17, 2003; Revised Manuscript Received November 17, 2003

\begin{abstract}
The interaction between trivalent lanthanide ions and the polymer poly $(1,4,7,10$-tetraoxacyclododecan-2-ylmethyl methacrylate) (PCR4) containing pendant 1,4,7,10-tetraoxacyclododecane (12crown-4) groups has been studied by various spectroscopic techniques, calorimetry and theoretical calculations. Evidence for the binding of $\mathrm{Eu}(\mathrm{III}), \mathrm{Tb}(\mathrm{III})$, and $\mathrm{Ce}(\mathrm{III})$ ions and PCR4 in solution was obtained by the lanthanide-induced ${ }^{1} \mathrm{H}$ and ${ }^{13} \mathrm{C} N \mathrm{NM}$ shifts and the decay of $\mathrm{Tb}(\mathrm{III})$ luminescence. From the isotope effect observed on the decay of luminescence of $\mathrm{Tb}(\mathrm{III})$ bound to PCR4 in $\mathrm{H}_{2} \mathrm{O}$ and $\mathrm{D}_{2} \mathrm{O}$ solutions, it is suggested that complexation leads to a decrease in the number of water molecules from 8 or 9 to 7. In the solid state, studies by differential scanning calorimetry (DSC) show that the interaction between $\mathrm{Ce}(\mathrm{III}), \mathrm{Tb}(\mathrm{III})$, and $\mathrm{Li}(\mathrm{I})$ ions and PCR4 leads to an increase in the glass transition temperature $\left(\mathrm{T}_{\mathrm{g}}\right)$ of the polymer. Electron paramagnetic resonance (EPR) spectra of Gd(III) in the presence of the polymer are quite similar to those in aqueous solution, while $\mathrm{Tb}(\mathrm{III})$ emission is quenched by $\mathrm{Ce}(\mathrm{III})$ with nearly the same rate constants in water and aqueous PCR4 solutions, and the Ce(III) emission maxima are only very slightly shifted in the presence of the polymer, all suggesting relatively weak dynamicinteraction between the cations and the crown ether. However, isotope effects on the $\mathrm{Tb}(\mathrm{III})$ luminescence lifetime confirm complexation. From the lanthanide-induced ${ }^{1 \mathrm{H}}$ and ${ }^{13} \mathrm{C} \mathrm{NMR}$ shifts the stability constants of the 1:1 complexes formed have been calculated for both $\mathrm{Tb}(\mathrm{III})$ and $\mathrm{Eu}(\mathrm{III})$, yielding values 22.5 and 1.9, respectively. The agreement between the constants cal culated from ${ }^{1} \mathrm{H}$ and ${ }^{13} \mathrm{C} \mathrm{NMR}$ shifts are very good and the low values of the calculated stability constants confirm the weak binding of the lanthanide ions by the crown ether. Results of ab initio calculations are al so reported, where the interactions are model ed for 12-crown-4/La(III ) complex and bond energies determined.
\end{abstract}

\section{Introduction}

In 1967 Charles J. Pedersen published two papers describing the binding of alkali metal ions (lithium, sodium, potassium, rubidium, and cesium) to compounds he called crown ethers. ${ }^{1,2}$ These compounds are cyclic polyethers made up of ethylene glycol units, $\left(\mathrm{OCH}_{2} \mathrm{CH}_{2}\right)_{n}$, while the name crown derives from the appearance of space filling models of the compound and the ability of these compounds to "crown" cations. These compounds have attracted the attention of chemists over the last 30 years, and the importance of crown ethers and related compounds has been recognized with the award of the 1987 Nobel Prize to Professors Pedersen, Cram, and Lehn for their pioneering work in this area.

The ability of organic molecules to bind metal ions is not limited to the free crown ethers, such as 1,4,7,10tetraoxacyclododecane (12-crown-4). Polymers with pendant crown ethers are of considerable interest and importance and are expected to show different selectivity from their monomers in complex formation with metal cations. Much of the main focus of crown ether structures is now directed toward the inclusion of these supramolecules in a polymer matrix or in a polymer structure due to the enormous possibilities these systems present in high technology applications, such as, sensors, ${ }^{3}$ actuators, ${ }^{4}$ permselective membranes, ${ }^{5}$ cata-

\footnotetext{
$\dagger$ Universidad de Burgos.

₹ Universidade de Coimbra.

* To whom correspondence should be addressed. Facultad de Ciencias. Telephone: 0034947 258061. Fax:0034 947258831. E-mail: mjtapia@ubu.es.
}

lysts, ${ }^{6}$ and so on, related to the fact that crown ether can selectively recognize alkali, alkaline earth metal ions, and other cations, including lanthanides, actinides, and transition metals. Considering the dependence that many of these potential technological applications of the polymer-bound crown ethers have on their interaction with metal ions, it is of great interest to study the interaction between metal ions and crown ether polymers directly. However, the problem at the molecular level with alkali and alkaline earth ions is the limited number of spectroscopic properties available to study polymer-metal interaction. In this respect, trivalent lanthanides are very useful tools because, on one hand, they can replace metal ions such as $\mathrm{Ca}(\mathrm{II}), \mathrm{Zn}(\mathrm{II})$, $\mathrm{Mg}(\mathrm{II}), \mathrm{Mn}(\mathrm{II}), \mathrm{Fe}(\mathrm{II})$, and $\mathrm{Fe}(\mathrm{III})$ in many systems, including biological ones, where they have been shown to provide information about the biochemical processes, ${ }^{7}$ and at the same time they are observable by a variety of spectroscopic techniques. ${ }^{8}$ In nuclear magnetic resonance spectroscopy (NMR), lanthanides are used as shift reagents. ${ }^{9,10}$ In addition, $\mathrm{Gd}(\mathrm{III})$ can act as an electron paramagnetic resonance (EPR) probe. ${ }^{11}$ Further, they exhibit excellent electronic properties which makes them valuable as luminescent probes.8,12,13 Several studies have already been presented using lanthanides as probes in crown ether polymers. ${ }^{14,15}$

Recently, we have reported detailed studies of the interaction of lanthanides with different surfactant and polymeric systems, using mainly luminescence and E PR techniques. In particular, we have studied interaction of these cations with sodium dodecyl sulfate (SDS) 

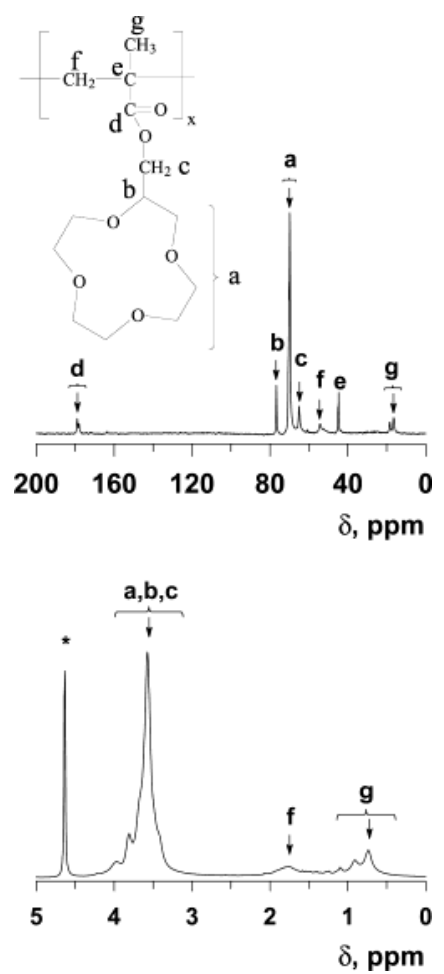

Figure 1. Structure of PCR4, together with and ${ }^{13} \mathrm{C}$ and ${ }^{1} \mathrm{H}$ NMR spectra (upper and lower spectra, respectively) and signal assignments.

micelles, ${ }^{16}$ bis(2-ethylhexyl) sulfosuccinate (AOT)/water/ isooctane microemulsions, ${ }^{17}$ and the polyelectrolyte sodium poly(vinyl sulfonate) (PVS). ${ }^{18}$ The systems studied so far have all been anionic. We extend these studies to consideration of the interactions of Ianthanide cations with an uncharged water-soluble polymethacrylate containing a pendant 12-crown-4 ether structure. We have chosen the poly $(1,4,7,10$-tetraoxacyclododecan-2ylmethyl methacrylate), because the discrete 12-crown-4 molecule is one of the best and most widely studied crown ethers in metal extraction and both the polymer and the polymer-metal complexes are water soluble which facilitates the extractability. ${ }^{19}$ This makes the study of crown ether-metal interaction particularly interesting. Although, this is not the optimum size (crown-4 cavity size radii, $60-75 \mathrm{pm}$ ) ${ }^{19}$ for incorporating lanthanide ions (ionic radii, around $95 \mathrm{pm}$ ), it provides a good starting point for a systematic study on the interaction between these cations and polymer based crown ethers. Similar compounds but with larger crown size (crown 5 and 6) are currently being synthesized to enable a comparative study of the effect of the crown size on the crown polymer-metal interaction. The polymer poly $(1,4,7,10$-tetraoxacycl ododecan-2-ylmethyl methacrylate) structure, from now on referred to as PCR4, is depicted in Figure 1. Polymers with pendent structures can be prepared either by the polymerization of monomers containing the pendent structures or by the reaction of polymer with appropriate substrates. The former method has been followed and is preferable for studies on basic properties, since it gives a well-defined regular polymer without leaving any unreacted acid groups. This facilitates the analysis of results and provides a useful basis for any structure-property relationships.

To el ucidate the metal-polymer interaction in these systems in aqueous solution, ${ }^{1} \mathrm{H}$ and ${ }^{13} \mathrm{C} N M R, E P R$, and Iuminescence spectroscopic techniques have been used. The chemical shift increments in the ${ }^{1} \mathrm{H}$ and ${ }^{13} \mathrm{C}$ NMR spectra permit calculation of the stability constants of the complexes formed. In addition, cationpolymer interaction in the solid state has been evaluated using DSC measurements.

Finally, some ab initio calculations have been performed to allow a qualitative evaluation of the energetic stabilization induced by the metal-ion interaction.

\section{Materials and Methods}

Reagents. Cerium(III), terbium(III), europium(III), and gadolinium(III) perchlorates (40\% water solution) and deuterium oxide (99.9\%) were purchased from Aldrich and used without further treatment. Millipore-Q water was used to prepare all solutions.

Apparatus and Methods. For steady-state luminescence spectral measurements, a Shimadzu RF-5301 PC instrument was used in right-angle configuration. $\mathrm{Tb}(\mathrm{III})$ luminescence lifetimes were measured using the Spex 1934D phosphorimeter accessory with a J obin-Yvon-Spex Fluorolog 3-22 instrument, and decays were analyzed using Origin 5.0 software. Electron paramagnetic resonance measurements were carried out in aqueous solutions with samples in the sealed capillary part of Pasteur pi pets; all spectra have been corrected for the background signal of the glass. Spectra were recorded on a Bruker EMX10/12 spectrometer, equipped with Bruker $\mathrm{N}_{2}$ temperature controller device BVT3000, operating at $X$ band and calibrated with DPPH $\left(\alpha, \alpha^{\prime}\right.$-dipheyl- $\beta$-picrylhydrazyl). The NMR spectra of polymers were recorded on a Varian I NOVA 400 spectrometer operating at $399.92 \mathrm{MHz}\left({ }^{1} \mathrm{H}\right)$ and 100.57 $\mathrm{MHz}\left({ }^{13} \mathrm{C}\right)$, using $\mathrm{D}_{2} \mathrm{O}$ or $\mathrm{CDCl}_{3}$ as solvent. All luminescence, NMR and EPR spectra have been registered at 20 ${ }^{\circ} \mathrm{C}$. The thermal properties of the polymer and lanthanidepolymer complex were determined calorimetrically with a Perkin-EImer Pyris I calorimeter at a heating rate of $10{ }^{\circ} \mathrm{C}$ $\min ^{-1}$.

Synthesis of Monomer and Polymers. 1,4,7,10-T etraoxacyclododecan-2-ylmethanol and 1,4,7,10-tetraoxacyclododecan2-ylmethyl methacrylate (CR4MA) were prepared according to the synthetic procedures described by Tiemblo et al. ${ }^{20}$ and García et al. ${ }^{21}$ The radical polymerization of CR4MA to form PCR4 and the subsequent purification were accomplished following the procedure described by García et al. ${ }^{22}$

Polymer Characterization. The structure of the polymer PCR4 (Figure 1) was confirmed by ${ }^{1} \mathrm{H}$ and ${ }^{13} \mathrm{C}$ NMR spectroscopy. The tacticity of the polymer was determined by ${ }^{13} \mathrm{C} N \mathrm{NR}$ spectroscopy: an average molar fraction of syndiotactic diads of $0.83 \pm 0.05$ was obtained. Comparison of this with the values of the triad and pentad units indicates Bernoullian stereochemical control.23 The predominance of syndiotactic over isotactic sequences is similar to that found for other methacrylic polymers. ${ }^{24}$

The glass transition temperature $\left(T_{g}\right)$, determined by DSC and taken at the onset of the separation of the endotherm from the baseline in the glassy region, was $32{ }^{\circ} \mathrm{C}$.

\section{Results and Discussion}

Magnetic Resonance Spectroscopic Results.

${ }^{1} \mathbf{H}$ and ${ }^{13} \mathbf{C}$ NMR Results. To gain insight into the lanthanide-PCR4 interactions, ${ }^{1} \mathrm{H}$ and ${ }^{13} \mathrm{C}$ NMR spectra of PCR4 (7 wt \%, corresponding to $0.25 \mathrm{M}$ in terms of monomer units) solutions in $\mathrm{D}_{2} \mathrm{O}$ were measured at $20^{\circ} \mathrm{C}$ with various additions of $\mathrm{Eu}(\mathrm{III})[(2 \times$ $\left.\left.10^{-4}\right)-0.6 \mathrm{M}\right]$ or $\mathrm{Tb}(\mathrm{III})\left[\left(2 \times 10^{-4}\right)-0.2 \mathrm{M}\right]$. The high $\mathrm{Tb}$ (III) paramagnetism limits the maximum cation concentration to $0.2 \mathrm{M}$ for such studies. Upon addition of either $\mathrm{Eu}(\mathrm{III})$ or $\mathrm{Tb}(\mathrm{III})$, shifts of the proton and carbon resonances to higher magnetic fields and signal broadening were observed, as shown in Figure 2 for 


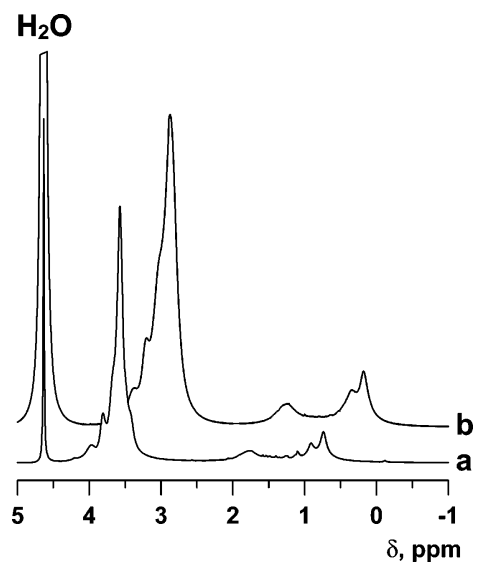

Figure 2. PCR4 (a) and $\mathrm{Tb}(\mathrm{III})-\mathrm{PCR} 4$ (b) ${ }^{1} \mathrm{H}$ NMR spectra. $\mathrm{Tb}(\mathrm{III})$ concentration, $6 \times 10^{-2} \mathrm{M}$.

the ${ }^{1} \mathrm{H}$ NMR spectrum of $\mathrm{Tb}(\mathrm{III})-\mathrm{PCR} 4$. The induced shifts are higher for $\mathrm{Tb}(\mathrm{III})$ than for $\mathrm{Eu}(\mathrm{III})$, in agreement with the weaker paramagnetism of the latter species. ${ }^{25}$

The chemical shift increments of proton and/or carbon resonance have been obtained by subtracting the polymer-lanthanide signal shifts from the polymer chemical shifts. The largest ${ }^{1} \mathrm{H}$ and ${ }^{13} \mathrm{C}$ shifts are observed for the crown ( $a$ and b) signals, confirming that the lanthanides interact with PCR4 mainly through the crown ether group (12-crown-4). We will now address the use of the shift increments of proton and carbon resonances to calculate the stability constants.

Determination of Stability Constants. The adimensional stability constant for formation of the $n: m$ complex $\left(\mathrm{C}_{\mathrm{nm}}\right)$ between the lanthanide ion $(\mathrm{L})$ and crown (C) is given by

$$
\mathrm{K}_{\mathrm{nm}}=\frac{\left[\mathrm{C}_{\mathrm{nm}}\right]}{[\mathrm{L}]^{\mathrm{m}}[\mathrm{C}]^{\mathrm{n}}}
$$

Assuming fast exchange conditions, the observed chemical shift for a guest atom is expressed as

$$
\delta_{\text {obs }}=\mathrm{f}_{\mathrm{C}} \delta_{\mathrm{C}}+\mathrm{nf}_{\mathrm{C}_{\mathrm{nm}}} \delta_{\mathrm{C}_{\mathrm{nm}}}
$$

where $\delta_{\mathrm{C}}$ and $\delta_{\mathrm{C}_{\mathrm{nm}}}$ represent the chemical shift of a given nucleus when free and complexed $C$, and $f_{C}$ and $f_{C_{n m}}$ are their molar fractions, respectively.

The chemical shift displacement of a given nucleus of the crown, $\mathrm{C}$, can be expressed as

$$
\Delta \delta_{\mathrm{obs}}=\frac{\mathrm{n} \Delta \delta_{\mathrm{C}_{\mathrm{nm}}}}{[\mathrm{C}]_{0}}\left[\mathrm{C}_{\mathrm{nm}}\right]
$$

which, for the 1:1 complex, after some algebraic manipulation and simplification, results in

$$
\begin{aligned}
\Delta \delta_{\text {obs }}= & \frac{\Delta \delta_{\mathrm{C}_{11}}}{2[\mathrm{C}]_{0}}\left\{[\mathrm{~L}]_{0}+[\mathrm{C}]_{0}+\frac{1}{\mathrm{~K}_{11}}-\right. \\
& \left.\left(\left([\mathrm{L}]_{0}+[\mathrm{C}]_{0}+\frac{1}{\mathrm{~K}_{11}}\right)^{2}-4[\mathrm{~L}]_{0}[\mathrm{C}]_{0}\right)^{1 / 2}\right\}
\end{aligned}
$$

while for the 2:1 case one obtains

$$
\begin{array}{r}
\Delta \delta_{\mathrm{obs}}=\Delta \delta_{\mathrm{C}_{21}}\left\{4[\mathrm{~L}]_{0}[\mathrm{C}]_{0}+[\mathrm{C}]_{0}^{2}+\frac{1}{\mathrm{~K}_{21}}-\right. \\
\left(\left(4[\mathrm{~L}]_{0}[\mathrm{C}]_{0}+[\mathrm{C}]_{0}^{2}+\frac{1}{\mathrm{~K}_{21}}\right)^{2}-16[\mathrm{~L}]_{0}[\mathrm{C}]_{0}{ }^{2}\left([\mathrm{C}]_{0}+\right.\right. \\
\left.\left.\left.[\mathrm{L}]_{0}\right)\right)^{1 / 2}\right\} / 4[\mathrm{C}]_{0}\left([\mathrm{C}]_{0}+[\mathrm{L}]_{0}\right)
\end{array}
$$

(see ref 26 for the complete derivation of the above equations) where $[C]_{0}$ and $[L]_{0}$ are the initial concentration of crown units and lanthanides, respectively.

The experimental data can be fitted to the corresponding expression, using a nonlinear least-squares algorithm, to obtain the fitting parameters $\mathrm{K}_{\mathrm{nm}}$ and $\Delta \delta_{\mathrm{C}_{\mathrm{nm}}}$. This and similar approaches ${ }^{27}$ have been used with some success for the determination of large stability constants, frequently in conjunction with ratios extracted from J ob plots. However, for low values of [C $]_{0}$ and $[\mathrm{L}]_{0}$ and/or low values of $K_{n m}$, the use of these equations may pose some problems, which we illustrate for the simpler 1:1 case. Similar results can be obtained for the 2:1 equation. When $\mathrm{y}$ is sufficiently small $\mathrm{x}-$ $\sqrt{x^{2}-\mathrm{y}} \approx \mathrm{y} / 2 \mathrm{x}$, and eq 4 reduces to

$$
\Delta \delta_{\mathrm{obs}}=\frac{\Delta \delta_{\mathrm{C}_{11}}}{\mathrm{M}+\left(1 / \mathrm{K}_{11}\right)}[\mathrm{L}]_{0}
$$

where $M=[C]_{0}+[L]_{0}$. If $M$ is kept constant in the experiments, as is common when J ob plots are concomitantly employed (in J ob's method the property which changes proportionally to the complex concentration is measured for a series of solutions in which $\mathrm{M}$ is constant while varying the ratio $\left.[\mathrm{L}]_{0} /[\mathrm{C}]_{0}\right),{ }^{28}$ the observed displacement varies linearly with $[\mathrm{L}]_{0}$ or $[C]_{0}$, but the fitting parameters are present in the form of a ratio that generates an infinite number of acceptable solutions. In this work, $M$ is varied and values attained are comparable to $1 / \mathrm{K}_{\mathrm{nm}}$.

Preliminary tests, conducted with eqs 4 and 5, have shown that the latter equation produced physically nonmeaningful results (excessively large complex displacements, $\Delta \delta_{\mathrm{C}_{\mathrm{nm}}}$ and correspondingly low stability constants, $\mathrm{K}_{21}$ ). However, by the use of eq 4, we have obtained the set of results depicted in Figure 3, for the proton and carbon nuclei of the crown group. The results for proton and carbon nuclei are almost coincident and point to the formation of a dominant 1:1 complex. The stability constants for complexes involving terbium are higher than those obtained for europium, in agreement with what can be anticipated from the respective ionic radii $(\mathrm{Eu}(\mathrm{III}), 98 \mathrm{pm}$, and $\mathrm{Tb}(\mathrm{III}), 93 \mathrm{pm}){ }^{29}$ These results are consistent with those of Rogers. ${ }^{30}$ The author has shown that a direct coordination of 12-crown-4 to hydrated terbium chloride in a ratio $1: 1$ is produced to render crystals of $\left[\mathrm{Tb}\left(\mathrm{OH}_{2}\right)_{5}(12\right.$-crown-4) $] \mathrm{Cl}_{3} \cdot 2 \mathrm{H}_{2} \mathrm{O}$ characterized by X-ray diffraction.

It is well established that lanthanide-induced shifts in NMR signals can have two contributions: a pseudocontact one coming from the through-space dipolar interactions and a contact contribution coming from direct delocalization of unpaired electron spin density from the metal. 8,25 Both contributions are expected to be largest for those atoms nearest the lanthanides and smallest for those which are most remote. ${ }^{8}$

Although separation of contact and pseudocontact contributions is not attempted at this stage, we strongly believe that with the nuclei in the crown ether rings 


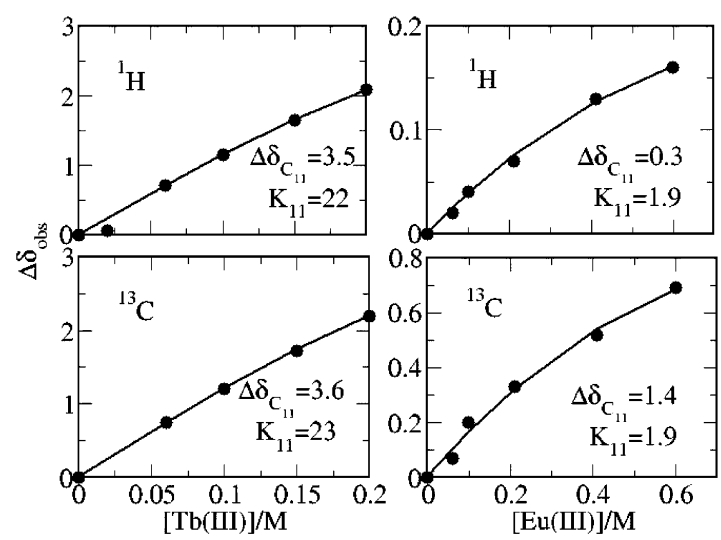

Figure 3. ${ }^{1} \mathrm{H} N M R$ and ${ }^{13} \mathrm{C} N M R$ chemical shift increments versus $\mathrm{Tb}(\mathrm{III})$ and $\mathrm{Eu}(\mathrm{III})$ molar concentration (crown ether nuclei $a$, according to Figure 1). The points are the experimental data and the line represents the fitted data for a 1:1 complex according to eq 4.

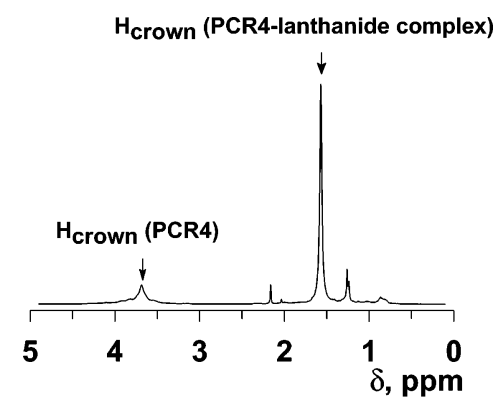

Figure 4. ${ }^{1} \mathrm{H}$ NMR spectra of PCR4- $\mathrm{Pe}(\mathrm{III})$ complex in $\mathrm{CDCl}_{3}$ with a 12-crown-4:Ce(III) molar ratio of 4:1.

there are important contact contributions because the proton shift ratios, taken relative to the most shifted proton $\left(\mathrm{H}_{\mathrm{a}}\right)$, for the polymer without lanthanide, depend on the particular lanthanide ion and on the lanthanide concentration. 8

The fact that NMR shifts depend on lanthanide concentration in aqueous solution implies that there is an equilibrium between complexed and uncomplexed pendent crown ether structure with metal ion in $\mathrm{D}_{2} \mathrm{O}$, and that this equilibrium is too fast to be observed on the NMR time scale (fast exchange limit), such that only a single average signal is recorded for each nucleus. In contrast with what happens in aqueous medium, in organic solvents instead of an average signal the lanthanide shifts do not depend on lanthanide concentration and two proton signals are observed, corresponding to the free crown group and to the lanthanide-crown complex. This was experimentally probed by measuring the ${ }^{1} \mathrm{H}$ NMR spectra of anhydrous PCR4-metal ion (Ce(III), Tb(III)) samples with molar ratios 2:1, 4:1, and 6:1 in $\mathrm{CDCl}_{3}$. As an example, part of the ${ }^{1} \mathrm{H}$ NMR spectrum of PCR4-Ce(III) (4:1) is shown in Figure 4, where proton resonances are observed for both the free crown group (3.7 ppm) and the lanthanide-crown complex (1.6 ppm). This means that in organic solvents either it is not possible to achieve equilibrium between complexed and noncomplexed lanthanide or it is too slow to be observed on the NMR time scale. The main difference between aqueous solutions and organic solvents is that in aqueous solution there is a competition between oxygen atoms of water molecules and crowns for lanthanide ions, while in organic solvent lanthanide ions can only interact with crown oxygen atoms.

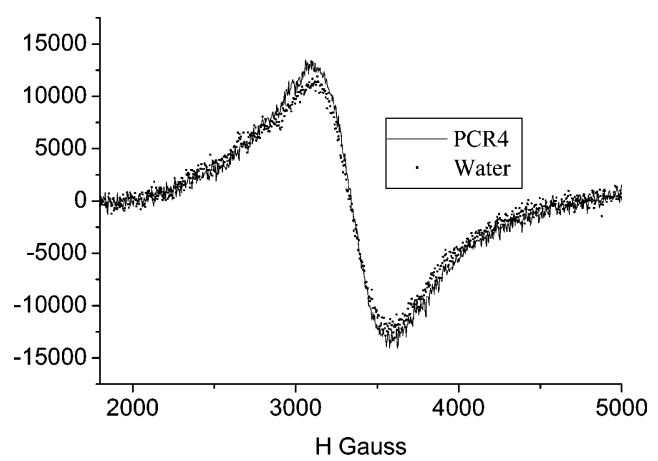

Figure 5. EPR spectra of $\mathrm{Gd}(\mathrm{III})\left(1 \times 10^{-3} \mathrm{M}\right)$ in PCR4 $(1 \%$ solution) and in aqueous solution.

Table 1. Lifetime of Tb(III) in PCR4 (1\%) in $\mathrm{H}_{2} \mathrm{O}$ or $\mathrm{D}_{2} \mathrm{O}$ Solutions

\begin{tabular}{ccc}
\hline Tb concn, M & $\tau_{\mathrm{D}_{2} \mathrm{O}}, \mathrm{ms}$ & $\tau_{\mathrm{H}_{2} \mathrm{O}}, \mathrm{ms}$ \\
\hline $6.4 \times 10^{-5}$ & 1.04 & 0.40 \\
$9.9 \times 10^{-5}$ & 1.16 & 0.37 \\
$2.0 \times 10^{-4}$ & 1.12 & 0.36
\end{tabular}

EPR Results. Further information on the interaction between lanthanides (III) and PCR4 is obtained from $\mathrm{Gd}(\mathrm{III})$ EPR spectroscopy. $\mathrm{Gd}(\mathrm{III})$, due to its high electron relaxation times in comparison to the other lanthanides, is the only one that gives EPR spectra at room temperature. ${ }^{8}$ The EPR spectra of $\mathrm{Gd}(\mathrm{III})$ at four $\mathrm{Gd}(\mathrm{III})$ concentrations $\left(1 \times 10^{-3}, 5 \times 10^{-3}, 1 \times 10^{-2}\right.$, and $4 \times 10^{-2} \mathrm{M}$ ) were measured in aqueous PCR4 solutions (1\%) and in pure water at $20^{\circ} \mathrm{C}$. The spectra were quite similar in the presence and absence of PCR4, as can be seen for the most dilute solutions in Figure 5, indicating that although the lanthanides are weakly bound to the PCR4, they possess considerable lateral mobility. This is in complete agreement with the observation of fast exchange in the NMR experiments, where average signals were observed for the free and lanthanide bound polymers.

Luminescence Results. Tb(III) Luminescence Decay. One of the most sensitive techniques to study the interaction between lanthanides and complexing species in aqueous solutions is the solvent isotope effect on the $\mathrm{Tb}$ (III) luminescence decay. The $\mathrm{Tb}$ (III) lifetime increases in $\mathrm{D}_{2} \mathrm{O}$ relative to $\mathrm{H}_{2} \mathrm{O}$ due to the reduced coupling of the lower energy $\mathrm{O}-\mathrm{D}$ oscillator compared with $\mathrm{O}-\mathrm{H}$ on the deactivation of the excited lanthanide ions. These $\mathrm{Tb}(\mathrm{III})$ lifetime changes provide a quantitative method to determine the number of coordinated water molecules. $12,31,32 \mathrm{~Tb}$ (III) fluorescence de cays were measured for three different metal ion concentrations $\left(6.4 \times 10^{-5}, 9.9 \times 10^{-5}\right.$, and $\left.2 \times 10^{-4} \mathrm{M}\right)$ in PCR4 solutions at $1 \%$ (weight/volume, w/v) aqueous (or $\mathrm{D}_{2} \mathrm{O}$ ) solutions at $20{ }^{\circ} \mathrm{C}$. All the decays were monoexponential, and from the fits the lifetimes were determined (Table 1).

From the average $\mathrm{Tb}(\mathrm{III})$ lifetimes in aqueous solution and in $\mathrm{D}_{2} \mathrm{O}$, the average number of water molecules coordinated to $\mathrm{Tb}(\mathrm{III})$ in the PCR4 system is 7.2 , while in aqueous solution $\mathrm{Tb}(\mathrm{III})$ coordinates between eight and nine water molecules. ${ }^{33}$ The loss of coordinated water molecules is a common effect that we have observed in several other systems as a consequence of the various kinds of interaction between $\mathrm{Tb}(\mathrm{III})$ ions and the system. With sodium dodecyl sulfate, SDS, micelles $\mathrm{Tb}$ (III) loses one water molecule, ${ }^{16}$ in bis(2-ethylhexyl) sulfosuccinate (AOT) water/isooctane mi croemulsi ons it loses two water molecules, ${ }^{17}$ and in the polyelectrolyte 


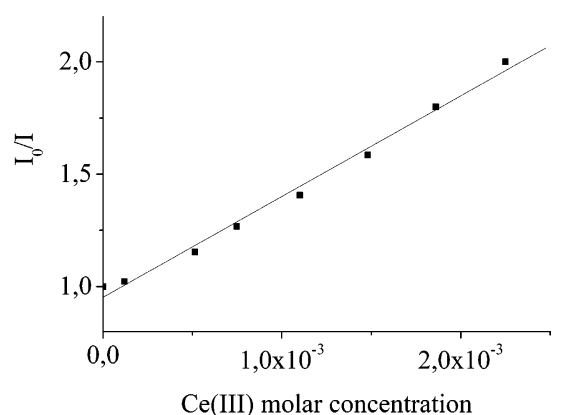

Figure 6. Stern-Volmer plot $(\mathrm{I} / \mathrm{l})$ of $\mathrm{Tb}(\mathrm{III})\left(10^{-2} \mathrm{M}\right)$ emission at $544 \mathrm{~nm}$ versus $\mathrm{Ce}(\mathrm{III})$ molar concentration. $\mathrm{I}_{0}$ and I are the $\mathrm{Tb}(\mathrm{III})$ emission intensities without and with $\mathrm{Ce}(\mathrm{III})$, respectively.

sodium poly(vinyl sulfonate) (PVS) the loss of six water molecules was observed. ${ }^{18}$ H owever, all these previous studies have involved negatively charged systems. ${ }^{16-18}$ In the present case, a neutral polymer was studied and these experiments strongly suggest that water loss also occurs in the interaction between Tb(III) ions and PCR4 in aqueous solution. A loss of water coordination molecules as a consequence of the interaction between $\mathrm{Tb}(\mathrm{III})$ and 12-crown-4 has been also probed to take place in solid state for a structurally related complex: $\left[\mathrm{Tb}\left(\mathrm{OH}_{2}\right)_{5}\left(12\right.\right.$-crown-4)] $\mathrm{Cl}_{3} \cdot 2 \mathrm{H}_{2} \mathrm{O} .30$

Ce(III) Emission. Ce(III) luminescence can also provide valuable information on the interaction of lanthanides in these systems. For all the previously studied charged systems (SDS, PVS, and AOT) the spectroscopically al lowed $4 \mathrm{f} \rightarrow 5 \mathrm{~d} \mathrm{Ce}(\mathrm{III})$ emission ${ }^{34}$ was found to be blue-shifted about $4 \mathrm{~nm}$ on binding. ${ }^{16,17}$ However, in PCR4 (1\%) the cerium(III) emission is quenched and red-shifted $1 \mathrm{~nm}$. This red shift can be due to scattering. ${ }^{35}$ This means, on one hand, that $\mathrm{Ce}(\mathrm{III})$ emission is not as sensitive as $\mathrm{Tb}(\mathrm{III})$ lifetime measurements to the lanthanide(III)-PCR4 interaction and, on the other hand, it means that lanthanide(III) interaction with uncharged systems is weaker than that with charged systems. The trivalent lanthanides $(\mathrm{Ln}(\mathrm{III}))$ can be considered as "hard" acids in the Pearson classification that bind negatively charged groups via ionic bonding interaction and also tend to bind the most electronegative ligand atoms. Although the binding preference is with groups having negatively charged groups (with the preference following the order $\mathrm{O}>\mathrm{N}>\mathrm{S}),{ }^{13} \mathrm{Ln}(\mathrm{III})$ in aqueous solution can also strongly bind donor groups containing neutral oxygen or nitrogen atoms only when present in multidentate ligands that contain at least one or two other donor groups having negatively charged oxygens. However, there are some exceptions and very weak binding of Ln(III) to carbohydrates and nucleosides has also been observed. ${ }^{13}$ In our case, since the oxygens in the 12 crown-4 group are uncharged, only weak binding of $\mathrm{Ln}(\mathrm{III})$ is expected in PCR4. This is in agreement with the above results, where the interaction is only detected using the more sensitive techniques of NMR and $\mathrm{Tb}$ (III) lifetime measurements.

Tb(III) Quenching by Ce(III). Quenching of Tb(III) emission by $\mathrm{Ce}(\mathrm{III})$ in aqueous PCR4 solution (1\%) was studied adding $\mathrm{Ce}(\mathrm{III})$ in the concentration range between $1.19 \times 10^{-4}$ and $2.25 \times 10^{-3} \mathrm{M}$ to solutions with $\mathrm{Tb}(\mathrm{III})\left(10^{-2} \mathrm{M}\right)$ at $20{ }^{\circ} \mathrm{C}$. Quenching follows good Stern-Volmer kinetics as seen in Figure 6. Tb(III) quenching is probably due to energy transfer to a lowlying state of $\mathrm{Ce}(\mathrm{III})$. The cal culated quenching constant,

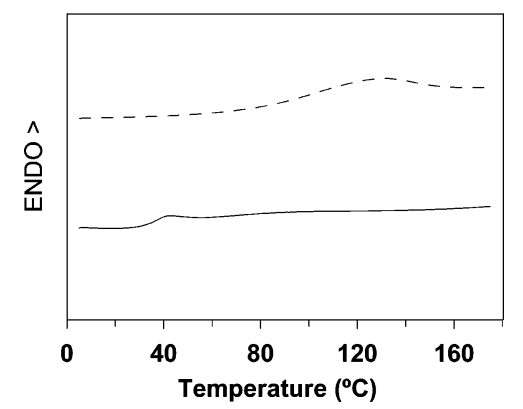

Figure 7. DSC of PCR 4 (continuous line) and PCR4-Ce(III) complex with a crown number to metal number ratio of $6: 1$ (dashed line).

$\mathrm{k}_{\mathrm{q}}=1.1 \times 10^{5} \mathrm{M}^{-1} \mathrm{~s}^{-1}$, is identical to that obtained in (AOT) water/isooctane microemulsions ${ }^{17}$ and comparable to the value for pure water $\left(k_{q}=1.4 \times 10^{5} \mathrm{M}^{-1}\right.$ $\left.\mathrm{s}^{-1}\right) .{ }^{16}$ These results suggest that the lanthanide $d y-$ namics under our experimental conditions are quite similar to those in aqueous solution, in agreement with the results of the Gd(III) EPR spectra (Figure 5), which are not affected by the presence of PCR4 (1\%) showing similar dynamics of the cation in the presence and absence of the polymer.

Similar experiments were carried out in the presence of $\mathrm{LiCl}$ with a constant ionic strength $(0.1 \mathrm{M})$ in aqueous solution and in PCR4 (1\%) solutions. In both cases the quenching constant is slightly reduced to $\mathrm{k}_{\mathrm{q}}=1.0 \times 10^{5}$ $\mathrm{M}^{-1} \mathrm{~S}^{-1}$. From these experiments it can be concluded that the ionic strength does not significantly affect the quenching process, although nothing can be deduced from these results about the competition between lithium and lanthanides for interacting with the PCR4 polymer since the quenching processes both in PCR4 and bulk water are very similar.

Calorimetric Results. Magnetic resonance and fluorescence studies have confirmed a weak interaction between the metal center in lanthanide salts and the pendent crown structure of the polymethacrylate PCR4 in aqueous solution. It is probable that these interactions will be stronger in the solid state, taking into account the fact that there is no competition in this case for the cation between oxygen atoms in crown ethers and water.

The effect on cation binding in the solid state was studied by means of differential scanning calorimetry, following the effect of the complex formation on the glass transition temperature of the polymer-cation system (Figure 7). Results are compared with those obtained from polymer-lithium ion system, which is thought to form a 1:1 complex (ligand to metal). ${ }^{36}$ Solid samples were obtained by freeze-drying of aqueous solutions of PCR4 (1\%) with different quantities of $\mathrm{Eu}(\mathrm{III}), \mathrm{Tb}(\mathrm{III})$, or $\mathrm{Li}(\mathrm{I})$. For each metal, three different colorless transparent films were obtained, with a molar ratio of crown in the polymer structure to metal ions of $2: 1,4: 1$, and 6:1.

In the PCR4-lithium ion system, the glass transition temperature $\left(T_{g}\right)$ showed a linear increase with the increment in the molar metal content to 12-crown-4 moieties in the pendent chains. The data obtained are summarized in Table 2. For the crown-to-metal ratio $6: 1, \mathrm{~T}_{\mathrm{g}}$ increments of 17,48 , and $59{ }^{\circ} \mathrm{C}$ are observed for $\mathrm{Li}(\mathrm{I}), \mathrm{Ce}(\mathrm{III})$, and $\mathrm{Tb}(\mathrm{III})$, respectively. When $\mathrm{T}_{\mathrm{g}}$ is reached, the restriction in the cooperative segmental movements in the polymer backbone is released and suddenly massive cooperative motions start to occur. 
Table 2. Glass Transition Temperatures, $T_{g}$, of PCR 4 and PCR4-Metal Complexes

\begin{tabular}{lccc}
\hline & \multicolumn{3}{c}{$\mathrm{T}_{\mathrm{g}},{ }^{\circ} \mathrm{C}$} \\
\cline { 2 - 4 } (crown:metal) $^{\mathrm{a}}$ & $\mathrm{PCR} 4-\mathrm{Li}^{+}$ & $\mathrm{PCR}-\mathrm{Ce}^{3+}$ & $\mathrm{PCR}^{2}-\mathrm{Tb}^{3+}$ \\
\hline PCR4 without metal & 32 & 32 & 32 \\
6:1 & 49 & 80 & 91 \\
4:1 & 64 & & \\
2:1 & 94 & &
\end{tabular}

a Number of crown units in the polymer structure per metal ion.

This more marked effect of polymer-lanthanide ion complex formation on the increase of this thermal transition may be attributed to the higher hindrance to cooperative polymer chain motion due to the crownlanthanide ion complex, compared with the reduced hindrance to cooperative polymer motion due to the crown-lithium ion complex. The smaller 12-crown-4 is supposed to have an optimum cavity sizeto incorporate lithium cation.

An endothermic peak was observed for all the metalPCR4 systems. Unfortunately, this endothermic peak hinders the measurement of the $\mathrm{T}_{\mathrm{g}}$ of the PCR4$\mathrm{Ce}(\mathrm{III})$ and PCR4-Tb(III) systems for the ratios 4:1 and 2:1. This endothermic transition may correspond to the breaking the crown-metal interaction, but its enthal py could not be determined because of thermal decomposition before completion of this process.

The solid transparent films employed for the calorimetric studies were subsequently used to confirm reversibility of the dissolution/film formation processes with the polymers. The films were dissolved in $\mathrm{D}_{2} \mathrm{O}$, and the solutions were analyzed by ${ }^{1} \mathrm{H}$ NMR spectroscopy. The spectra were identical with those obtained in the previous NMR studies, confirming that the system is reversible and that the polymer was not altered upon freeze-drying and redissolving.

Molecular Modeling. Method and Results. Further information on the metal-crown ether interactions comes from molecular modeling. Gas-phase density functional theory (DFT) calculations have been performed with the Spartan program. ${ }^{37}$ The interaction between $\mathrm{La}(\mathrm{III})$ and one molecule of discrete 12-crown-4 [(12-crown-4)-La(III )] has been studied as a representative example of interaction of different trivalent lanthanides with crown ether compounds.

The geometry optimizations and energy evaluations were performed with DFT methods employing pseudopotentials at the RB3LYP/LACVP* level of theory for $\mathrm{La}$ (III) associated with the standard 3-21G* basis set for lighter elements. The bonding energies are defined as $\mathrm{E}_{\text {bond }}=\{\mathrm{E}$ (cation-molecule complex) $-[\mathrm{E}$ (molecule in the complex geometry) $+E$ (cation)] $\}$ where the cation is $\mathrm{La}(\mathrm{III})$ and the molecule is 12-crown-4.

The bond energy ( $\left.E_{\text {bond }}\right)$ and selected geometric parameters (distance of cation to crown oxygens) of the [(12-crown-4)La(III)] complex in the gas phase are shown in Table 3. $E_{\text {bond }}$ can be compared with the results described by J ohansson et al. ${ }^{38}$ for the tetra-, penta-, and hexaglyme-Li(I) complex. Polyglymes, as crown ether compounds, are molecules made up of ethylene glycol units, $\left(\mathrm{OCH}_{2} \mathrm{CH}_{2}\right)_{n}$, but with an open chain structure instead of a cyclic one. The bond energy per oxygen atom found in 12-crown-4-metal complex are higher than those obtained in the interaction between lithium ion and the open polyoxyethylene units. The difference arises mainly from the higher ability of crown
Table 3. Energies and Selected Geometry Parameters for (12-crown-4)-La(III) Interaction

\begin{tabular}{lccccc}
\hline & $\begin{array}{c}\text { mean } \\
\text { distance } \\
\text { cation- } \\
\text { Ocrown, } \AA\end{array}$ & $\begin{array}{c}\text { E total, } \\
\text { au }\end{array}$ & $\begin{array}{c}\mathrm{E}_{\text {bond }} \\
\text { total, } \\
\mathrm{kJ} \mathrm{mol}^{-1}\end{array}$ & $\begin{array}{c}\mathrm{EJ}_{\text {bond, }} \\
\mathrm{kJ}\end{array}$ \\
\hline 12-crown-4 & & $-615.641889 \mathrm{l}$ & & \\
(12-crown-4)-La(III) & 2.435 & -645.641889 & -1485 & -371
\end{tabular}

a Molecule in the complex geometry.

compounds to complex molecules compared with those with an open structure. However, in addition there are contributions due to the differences in the metal ion charge and radii. The distance between the cation and the crown oxygens are higher for the crown-metal complex in our systems than those calculated by J ohansson et al. ${ }^{38}$ due to the larger ionic radii of La(III) compared with $\mathrm{Li}(\mathrm{I})$. If the radii of both metals were subtracted from the distance discussed above, this value would be approximately the same for both systems. The calculated distance between $\mathrm{La}(\mathrm{III})$ and the crown oxygens are similar to that obtained by Rogers for the system $\left[\mathrm{Tb}\left(\mathrm{OH}_{2}\right)_{5}\left(12\right.\right.$-crown-4)]Cl $3 \cdot 2 \mathrm{H}_{2} \mathrm{O}$ in the solid state. $^{30}$

\section{Conclusions}

In summary, lanthanides interact weakly with the noncharged crown ether polymer PCR4 in aqueous solution. From the ${ }^{1} \mathrm{H}$ and ${ }^{13} \mathrm{C}$ NMR spectra we can conclude that these interactions take place mainly through bonding by the oxygens of the crown ether groups and also that in aqueous solution there is an equilibrium between the compl exed and noncomplexed lanthanide. This gives rise to average resonance signals. However, in organic solvents no equilibrium is detected and two proton resonance bands are observed for the crown hydrogen atoms. The interaction between lanthanides and PCR4 takes place with the loss of one to two water molecules. From the induced chemical shifts of ${ }^{1} \mathrm{H}$ and ${ }^{13} \mathrm{C} \mathrm{NMR}$, it is found that a weak $1: 1$ complex is predominantly formed with low stability constants. These were calculated in a coherent fashion using both proton- and carbon-induced NMR shifts. The weak interaction between lanthanides and PCR4 is confirmed by $\mathrm{Gd}(\mathrm{III})$ spectra and $\mathrm{Tb}(\mathrm{III})$ emission quenching, which are very similar in the presence of PCR4 and in pure aqueous solution. In addition, in the solid state, the metal-PCR4 interaction is indicated through the polymer $\mathrm{T}_{g}$, which increases in the presence of metals (17, 48, and $59^{\circ} \mathrm{C} \mathrm{T}_{\mathrm{g}}$ increments for $\mathrm{Li}(\mathrm{I}), \mathrm{Ce}(\mathrm{III})$, and $\mathrm{Tb}(\mathrm{III})$, respectively, with a CR4:metal ratio of 6:1). The fact that the ${ }^{1} \mathrm{H}$ NMR spectra of the redissolved complexes are identical to the ${ }^{1} H$ NMR spectra of freshly prepared complexes indicates that the freeze-drying and redissolving processes are reversible.

$\mathrm{Ab}$ initio calculations of the bond energy show that the interaction between one 12-crown-4 group with one $\mathrm{La}(\mathrm{III})$ ion is of the same order to those calculated by other authors for a comparable system but with Li(I), supporting the view that the proposed crown ethermetal 1:1 complex is reasonable from a theoretical point of view.

Acknowledgment. Financial support from Spanish J unta de Castilla y León and European Union (F.S.E.) (Bu09/01 and Bu16/02) and from Ministerio de Ciencia y Tecnología (FEDER-PIan Nacional de Investigación Científica, Desarrollo e Innovación Tecnológica, MAT- 
2002-02502) is gratefully acknowledged. H.D.B. and A.A.C.C.P. also thank POCTI, FCT, and FEDER for financial support.

\section{References and Notes}

(1) Pedersen, C. J . J . Am. Chem. Soc. 1967, 89, 7017-7036.

(2) Pedersen, C. J . J . Am. Chem. Soc. 1967, 89, 2495-2496.

(3) Drake P. L.; Price, G. J . Polym. Int. 2000, 49, 926-960.

(4) Shinkai, S.; Takeuchi, M.; Ikeda, A. Polymer Sensors and Actuators; Osada, Y., De Rossi, D. E., Eds.; Springer: Berlin, 2000; Chapter 6.

(5) Sata, T.; Sata, T.; Yang, W. J . Membr. Sci. 2002, 206, 3160.

(6) Watanabe, H.; Iijima, Y.; Fukuda, W.; Tomoi, M. React. Funct. Polym. 1998, 37, 101-109.

(7) Elbanowski, M.; Makowsca, B. J . Photochem. Photobiol. A. 1996, 99, 85-92.

(8) Bünzli, J . C. G.; Choppin, G. R. Lanthanides Probes in Life, Chemical and Earth Sciences; Elsevier: Amsterdam, 1989; Chapters 4, 6, and 7.

(9) Mayo, B. C. Chem. Soc. Rev. 1973, 2, 49-74.

(10) Williams, R. J. P. Struct. Bonding 1982, 50, 79-119.

(11) Borel, A.; Tóth, E.; Helm, L.; J ánossy, A.; Merbach, A. E. Phys. Chem. Chem. Phys. 2000, 2, 1311-1317.

(12) Horrocks, J r. De W.; Sudnick, D. R. Acc. Chem. Res. 1981 14, 384-392.

(13) Richardson, F. S. Chem. Rev. 1982, 82, 541-552.

(14) Liu, Y.; Han B. H.; Chen, Y. T. Coord. Chem. Rev. 2000, 200202, 53-73.

(15) Xia, W. S.; Schmehl, R. H.; Li, C. J . Tetrahedron 2000, 56, 7045-7049.

(16) Tapia, M. J .; Burrows, H. D.; Azenha, M. E. D. G.; Miguel, M. da G.; Pais, A. A. C. C.; Sarraguça, J. M. G. J . Phys. Chem. B 2002, 106, 6966-6972.

(17) Burrows H. D.; Tapia, M. J . Langmuir 2002, 18, 6706-6708.

(18) Tapia, M.J .; Burrows, H. D. Langmuir 2002, 18, 1872-1876.

(19) Khopkar, S. M. Analytical Chemistry of Macrocyclic and Supramolecular Compounds; Springer-Verlag: Berlin, 2002; Chapter 5.
(20) Tiemblo, P.; Guzmán, J .; Riande, E.; García, F.; García, J . M. Polymer 2003, 44, 6773-6780.

(21) García, F.; García, J . M.; Rubio, F.; Tiemblo, P.; Guzmán, J .; Riande, E. Polymer, in press.

(22) García, F.; De la Peña, J . L.; Delgado, J . J .; García, N.; Guzmán, J .; Riande, E.; Calle, P. J. Polym. Sci. Part A: Polym. Chem. 2001, 39, 1843-1853.

(23) Koenig, J . L. Chemical Microstructure of Polymer Chains; Wiley: New York, 1980; p 328.

(24) Matsumoto, A.; Mizuta, K.; Otsu, T. Macromolecules 1993 26, 1659-1695.

(25) André, J. P. R. F.; Burrows, H. D.; Geraldes, C. F. G. C. Miguel, M. Da Graça M.; Teixeira, M. H. S. F.; Boas, L. F. V. Polyhedron 1996, 15, 4331-4340.

(26) Ramos Cabrer, P.; Alvarez-Parrilla, E.; Meijide, F.; Seijas, J. A.; Rodríguez Núñez, E.; Vázquez Tato, J . Langmuir 1999, $15,5489-5495$

(27) Loukas, Y. L. J . Pharm. Pharmacol. 1997, 49, 944-948.

(28) Rossotti, H. The study of I onic Equilibria. An Introduction; Longman: London, 1978; p 120.

(29) Emsley, J . TheElements; Clarendon Press: Oxford, 1991; pp 66, 190.

(30) Rogers, R. D. Inorg. Chim. Acta 1987, 133, 175-180.

(31) Beeby, A.; Clarkson, I. M.; Eastoe, J .; Faulkner, S.; Warne, B. Langmuir 1997, 13, 5816-5819.

(32) Frey, S. T.; Horrocks, J r. De W. Inorg. Chim. Acta 1995, 229, 383-390.

(33) Horrocks, J r. De W.; Sudnick, D. R. J . Am. Chem. Soc. 1979, $101,334-340$

(34) Kaizu, Y.; Miyakawa, K.; Okada, K.; Kobayashi, H.; Sumitani, M.; Yoshihara, K. J. Am. Chem. Soc. 1985, 107, 2622-2626.

(35) Atherton, S. J .; Dymond, C. M. G. J . Phys. Chem. 1989, 93, 6809-6813.

(36) Parker, D. Crown Compounds: Towards FutureApplications; Cooper, S. R. Ed.; VCH: New York, 1992; Chapter 4.

(37) Spartan'02, Wave function. Inc., I rvine, CA.

(38) J ohansson, P.; Tegenfeldt, J .; Lindgren, J . Polymer 1999, 40, 4399-4406.

MA0353888 